J. Amer. Soc. Hort. ScI. 128(2):171-175. 2003.

\title{
Cytological and Ultrastructural Evaluations of Zinc Deficiency in Leaves
}

\author{
Tehryung Kim ${ }^{1}$ and Hazel Y. Wetzstein ${ }^{2}$ \\ Department of Horticulture, University of Georgia, Athens, GA 30602
}

\begin{abstract}
AdDitional INDEX wORDs. anatomy, Carya illinoinensis, zinc, deficiency, light microscopy, nutrition, transmission electron microscopy

Abstract. Zinc deficiency is a widespread nutritional disorder in plants and occurs in both temperate and tropical climates. In spite of its physiological importance, cytological and ultrastructural changes associated with zinc deficiency are lacking, in part because zinc deficiency is difficult to induce. A method was developed to induce zinc deficiency in pecan (Carya illinoinensis (Wangenh.) C. Koch) using hydroponic culture. Zinc deficiency was evaluated in leaves using light and electron microscopy. Zinc deficiency symptoms varied with severity ranging from interveinal mottling, overall chlorosis, necrosis, and marginal curving. Zinc deficient leaves were thinner, and palisade cells were shorter, wider, and had more intercellular spaces than zinc sufficient leaves. Cells in zinc deficient leaves had limited cytoplasmic content and accumulated phenolic compounds in vacuoles. Extensive starch accumulation was observed in chloroplasts. This work represents the first detailed microscopic evaluations of zinc deficiency in leaves, and provides insight on how zinc deficiency affects leaf structure and function.
\end{abstract}

Zinc is an essential micronutrient and involved in a number of important physiological activities. Zinc plays a role in membrane integrity, enzyme activation, gene expression and regulation, carbohydrate metabolism, anaerobic root respiration, protein synthesis, structural integrity of ribosomes, detoxification of superoxide radicals, phytohormone activity (e.g., auxin and gibberellic acid), gene structure (zinc finger motif), and disease resistance (Marschner, 1997). Reduced carbonic anhydrase level (Edwards and Mohamed, 1973; Randall and Bouma, 1973) and impaired Hill reaction activity (Spencer and Possingham, 1960) have been reported in zinc-deficient plants. Zinc deficiency is one of the most widespread nutritional disorders in plants grown under a wide range of soils, and is a common feature of both tropical and temperate climates (Cakmak et al., 1996; Graham et al., 1992; Rengel, 1995). Most studies on zinc deficiency have been limited to evaluations of growth, yield, and visual symptoms. There is little information on the cytological and ultrastructural effects of zinc deficiency, in spite of its importance in physiological and developmental aspects of plant function.

In pecan (Carya illinoinensis), nutritional problems frequently limit orchard productivity (Smith, 1991). Zinc deficiency in pecan has been reported since the early 1900s, and is related to soil pH and liming (Sparks, 1976). Rosette, a disorder in pecan resulting from inhibition of shoot elongation, has been recognized as a major cultural problem since the early part of the last century and discovered to be caused by zinc deficiency (as reviewed by Sparks, 1989). Researchers have reported the physiological impact of zinc deficiency in pecan, which includes decreased chlorophyll synthesis and gas exchange (Hu and Sparks, 1991), inhibition of reproductive development (Hu and Sparks, 1990), and decreased carbonic anhydrase activity (Snir, 1983). However, anatomical changes associated with zinc deficiency have not been studied. A void in our understanding of how zinc deficiency modifies leaf development and function exists. One of the main reasons for lack of work in this area is that zinc nutrition is difficult to control in the field. Plants require minute amounts

Received for publication 23 July 2002. Accepted for publication 16 Dec. 2002. ${ }^{1}$ Current address: Genetics Department, University of Georgia, Athens, GA 30602.

${ }^{2}$ Corresponding author; e-mail hywetz@uga.edu. of zinc for growth, and it is difficult to prevent zinc input from meteorological or chemical sources such as herbicides, pesticides and fertilizers. Furthermore, uptake of applied zinc is variable.

In our previous work, zinc deficiency was induced in pecan seedlings using hydroponic culture (Kim et al., 2002). The nutrient supply to plants during their development was critically controlled using this method. Plants exhibited a range of zinc deficiency symptoms, and foliar concentrations of zinc were related to the severity of deficiency symptoms. The objectives of this study were to define cytological and ultrastructural characteristics associated with zinc deficiency symptoms. This work represents the first detailed microscopic evaluations of zinc deficiency in leaves, and provides insight on how zinc deficiency affects leaf structure and function.

\section{Materials and Methods}

Plant materials. Pecan seeds collected from 'Curtis' trees were stratified in moist vermiculite at $4{ }^{\circ} \mathrm{C}$, in the dark for several months. Seeds were germinated in $12 \times 12 \times 20$-cm pots filled with perlite. Nutrients were supplied with full strength Hoagland's solution (Hoagland and Arnon, 1950) modified for pecan seedling growth as described later. Seedlings 10 to $15 \mathrm{~cm}$ tall with three to five leaves were obtained 3 weeks after planting. Seedlings used in the study were selected for uniformity.

Hydroponic CUlTURE. Seedlings were removed from the perlite and roots were washed with deionized water. Cotyledons were removed to eliminate them as a source of zinc supply to seedlings. Seedlings were transferred to hydroponic culture conditions in 15-L translucent pots (Rubbermaid Commercial Products, Winchester, Va.) that were painted on the outside with stainless steel emulsion paint (zinc free) to exclude light from the root zone. Tubing was placed in pots and air was bubbled continuously at a slow rate to provide aeration. Three plants per pot were suspended by foam collars in holes drilled through the lid. Plants were grown in a greenhouse at $25^{\circ} \mathrm{C}$ and light intensity at $70 \%$ of the integrated daily outside photosynthetically active radiation. Plants were acclimated to solution culture for 1 week in deionized water, followed by 1 week in one-fourth strength Hoagland's solution. Experiments were conducted in one-half strength Hoagland's solution with elemental concentrations of 
Table 1. Leaf thickness, palisade layer height, spongy layer height, epidermis cell height, and number of palisade cells per unit area for different zinc deficiency symptom ratings.

\begin{tabular}{|c|c|c|c|c|c|}
\hline $\begin{array}{l}\text { Symptom } \\
\text { rating }\end{array}$ & $\begin{array}{c}\text { Leaf } \\
\text { thickness } \\
(\mu \mathrm{m})\end{array}$ & $\begin{array}{c}\text { Palisade } \\
\text { layer } \\
\text { ht } \\
(\mu \mathrm{m})\end{array}$ & $\begin{array}{c}\text { Spongy } \\
\text { layer } \\
\text { ht } \\
(\mu \mathrm{m}) \\
\end{array}$ & $\begin{array}{c}\text { Epidermis } \\
\text { cell } \\
\text { ht } \\
(\mu \mathrm{m})\end{array}$ & $\begin{array}{c}\text { Palisade } \\
\text { cells/ } \\
100 \mathrm{~mm} \\
\text { (no.) } \\
\end{array}$ \\
\hline No symptom & $95 \pm 2.2^{z}$ & $40 \pm 1.6$ & $39 \pm 1.4$ & $8 \pm 0.7$ & $12 \pm 0.7$ \\
\hline Mild & $89 \pm 2.4$ & $36 \pm 1.0$ & $38 \pm 2.5$ & $10 \pm 0.4$ & $11 \pm 0.9$ \\
\hline Intermediate & $82 \pm 4.3$ & $29 \pm 2.6$ & $36 \pm 2.2$ & $11 \pm 1.0$ & $10 \pm 0.6$ \\
\hline Severe & $83 \pm 1.5$ & $30 \pm 2.2$ & $35 \pm 1.5$ & $11 \pm 0.6$ & $8 \pm 0.2$ \\
\hline
\end{tabular}

${ }^{\mathrm{z}}$ Mean \pm standard error; $\mathrm{n}=5$.

(in $\left.\mu \mathrm{M}\left(\mathrm{mg} \cdot \mathrm{L}^{-1}\right)\right): \mathrm{NO}_{3}{ }^{-}-\mathrm{N} 2700(37.8) ; \mathrm{NH}_{4}{ }^{+}-\mathrm{N} 2700(37.8) ; \mathrm{P} 500$ (15.5); K 1925 (75); Ca 1500 (60); Mg 1000 (24.3); S 3063 (98); B 8 (0.1); Cl 300 (10.7); Cu 0.16 (0.01); Fe 0.14 (0.01); Mn 4.6 (0.25); Mo 0.06 (0.01). In addition, the Hoagland's solution was modified to contain zinc at either 0 or $1.53 \mu \mathrm{M}\left(0.1 \mathrm{mg} \cdot \mathrm{L}^{-1}\right)$. Nutrient solutions were changed weekly. In plants grown in the absence of zinc, deficiency symptoms began to appear after 6 weeks in hydroponic culture. At 8 weeks, deficiency symptoms were obvious, and all samples were collected for histology and nutrient analyses.

EXPERIMENTAL DESIGN. For elemental analysis, a randomized complete block design was used with 48 plants (eight replications $\times$ two $\mathrm{Zn}$ concentrations $\times$ three plants per pot). For structural evaluation, five samples were collected for each symptom rating.

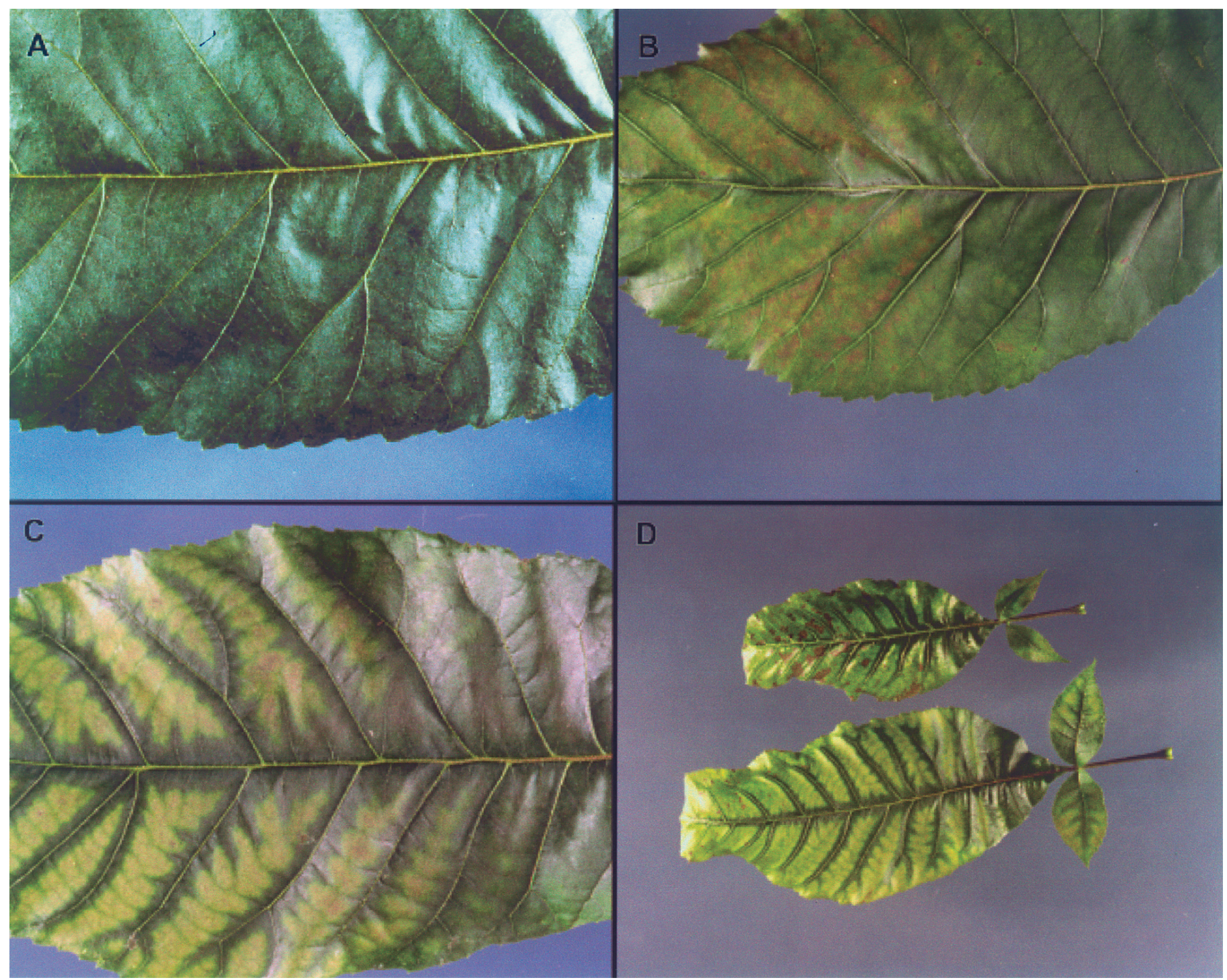

Fig. 1. Foliar symptoms of zinc deficiency. (A) Control leaf with uniform green color. (B) Leaf with mild zinc deficiency showing interveinal mottled regions. (C) Leaf exhibiting intermediate zinc deficiency symptoms with overall interveinal chlorosis. (D) Leaf with severe zinc deficiency symptoms exhibiting chlorosis, necrosis, puckering and distorted cup-shaped leaf blades. 


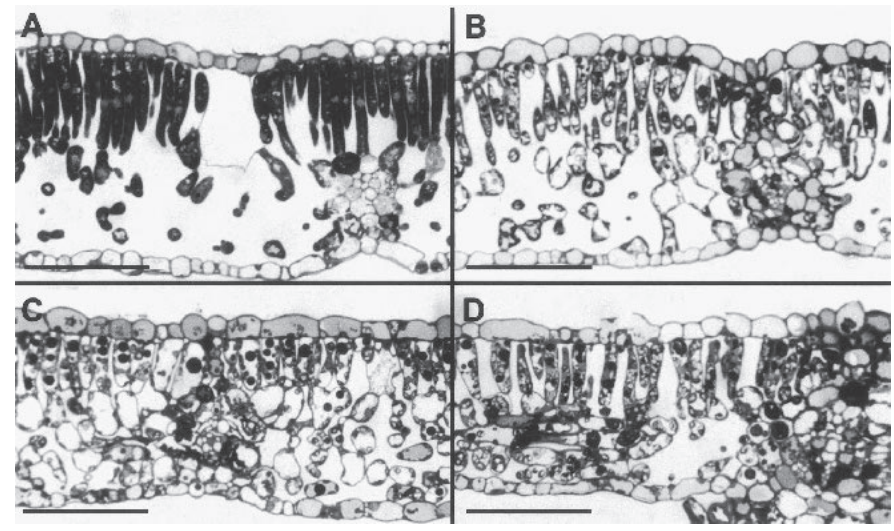

Fig. 2. Light micrographs of cross sections from leaves exhibiting different zinc deficiency symptoms. (A) Control leaf grown in the presence of zinc and exhibiting no deficiency symptoms. (B) Leaf with mild deficiency symptoms. (C) Leaf with intermediate deficiency symptoms. (D) Leaf with severe deficiency symptoms. All bars $=50 \mu \mathrm{M}$.

Elemental analysis. Individual leaves were rated for zinc deficiency according to the classification described in Table 1, and pooled for elemental analysis. To remove any dust or contamination that could affect nutrient concentrations, leaves were washed in deionized water with a mild soap, and rinsed in deionized water. Samples were oven dried at $80{ }^{\circ} \mathrm{C}$ to constant weight, then ground with a Wiley mill to pass a 20 -mesh sieve. A $0.5 \mathrm{~g}$ sample was ashed at $500{ }^{\circ} \mathrm{C}$ for $8 \mathrm{~h}$, then dissolved in $20 \%$ aqua regia $+10 \mathrm{ppm} \mathrm{Cd}$ solution. $\mathrm{Al}, \mathrm{B}, \mathrm{Ca}, \mathrm{Cu}, \mathrm{Fe}, \mathrm{K}, \mathrm{Mg}, \mathrm{Mn}$, $\mathrm{Mo}, \mathrm{Na}, \mathrm{P}$, and $\mathrm{Zn}$ were quantified in both leaf tissues and nutrient solutions using an ICAP (inductively coupled argon plasma spectrophotometer; Jarrel-Ash, Franklin, Mass.). $\mathrm{NO}_{3}{ }^{-} \mathrm{N}$ and $\mathrm{NH}_{4}{ }^{+} \mathrm{N}$ were quantified by a continuous flow nitrogen analyzer.

Microscopy. Within an individual plant, a range of foliar zinc symptoms was observed. Representative areas of selected leaves were sampled that exhibited deficiency symptoms ranging from mild to severe. All tissues were obtained from the middle region of the leaflet blades adjacent to the main veins. Samples were fixed in $2 \%$ glutaraldehyde with $0.1 \mathrm{~m}$ sodium cacodylate buffer ( $\mathrm{pH} 7.2$ ), then postfixed in $1 \%$ osmium tetroxide with $0.1 \mathrm{~m}$ sodium cacodylate buffer ( $\mathrm{pH}$ 7.2). Samples were dehydrated in a graded ethanol series after several washes with the $0.1 \mathrm{~m}$ sodium cacodylate buffer, then embedded in Spurr's medium (Spurr, 1969). Blocks were sectioned with an MT6000-XL ultramicrotome (RMC Inc., Tuscon, Ariz.). For light microscopy, thick sections $(\approx 1$ $\mu \mathrm{m})$ were collected on glass microscope slides and stained with toluidine blue. Cell dimensions were measured using a scale calibrated with a stage micrometer. The slides were examined with a microscope (Zeiss, Thornwood, N.Y.). For transmission electron microscopy, thin sections $(<100 \mathrm{~nm})$ were collected on Formvarcoated, gilded copper slot grids (Ted Pella, Redding, Calif.) and placed on Formvar-coated bridges to dry. The sections were poststained with $4 \%$ (w/v) aqueous uranyl acetate and Reynold's lead citrate (Reynold, 1963). The sections were examined with a transmission electron microscopy (Zeiss EM 902A; LEO Electron Microscopy, Thornwood, N.Y.) at $80 \mathrm{kV}$.

\section{Results and Discussion}

None of the seedlings grown with added zinc exhibited deficiency symptoms. Leaves from plants grown in the presence of zinc (Fig. 1A) were uniformly dark green in color, characteristic of leaves with sufficient nutrient levels. Deficiency symptoms began to appear after 6 weeks hydroponic culture in plants grown without zinc, and were confined to the youngest, most distal three to five leaves. The older, more proximal leaves in the no zinc treatment did not exhibit any nutritional disorder symptoms. Lack of zinc supply induced deficiency symptoms that ranged from mild to severe. Leaves with mild deficiency symptoms (Fig. 1B) were predominantly green but had interveinal mottled regions. Chlorosis was limited to the tip of the leaf, but $>50 \%$ of the leaf surface was a healthy dark green color. Leaves with intermediate symptoms (Fig. 1C) exhibited overall interveinal chlorosis. Some necrotic spots were observed also. Leaves with severe symptoms (Fig. 1D) had overall chlorosis, necrosis, puckering, and distorted cup-shaped leaf blades. These characteristics correspond with zinc deficiency symptoms observed in the field by others (Sparks, 1993). Zinc is known as an immobile element in plants (Mengel and Kirkby, 1982). Symptoms occur at the tip of young leaves first. Size decrease, including small leaves and rosetting, due to zinc deficiency has been reported in peach (Prunus Persica (L.) Batsch.) (Arce et al., 1992), citrus (Citrus sinensis L. and C. unshiu L.) (Bell et al., 1997), apple (Malus $\times$ domestica Borkh.) (Ganai et al., 1982), tomato (Lycopersicon esculentum L.) (Parker, 1992), navy bean (Phaseolus vulgaris L.) (Jolley and Brown, 1991), and wheat (Triticum aestivum L.) (Cakmak et al., 1996).

Nutrient analyses of leaf tissues verified that leaves were deficient in zinc. The severity of symptoms was related to the foliar zinc concentration. Leaves exhibiting mild, intermediate or severe symptoms had zinc concentrations of $9.79,9.56$, or 7.21 $\mu \mathrm{g} \cdot \mathrm{g}^{-1}$, respectively. The levels of the other essential elements were within the normal range. Control plants grown in the presence of zinc had leaf concentrations of $11.15 \mu \mathrm{g} \cdot \mathrm{g}^{-1}$. Leaf analysis is widely used by growers to assess nutritional status in pecan. On an orchard basis, the threshold value of leaf zinc that prevents deficiencies is proposed to be about $43 \mu \mathrm{g} \cdot \mathrm{g}^{-1}$ (Sparks and Payne, 1982), and is considerably higher than that on an

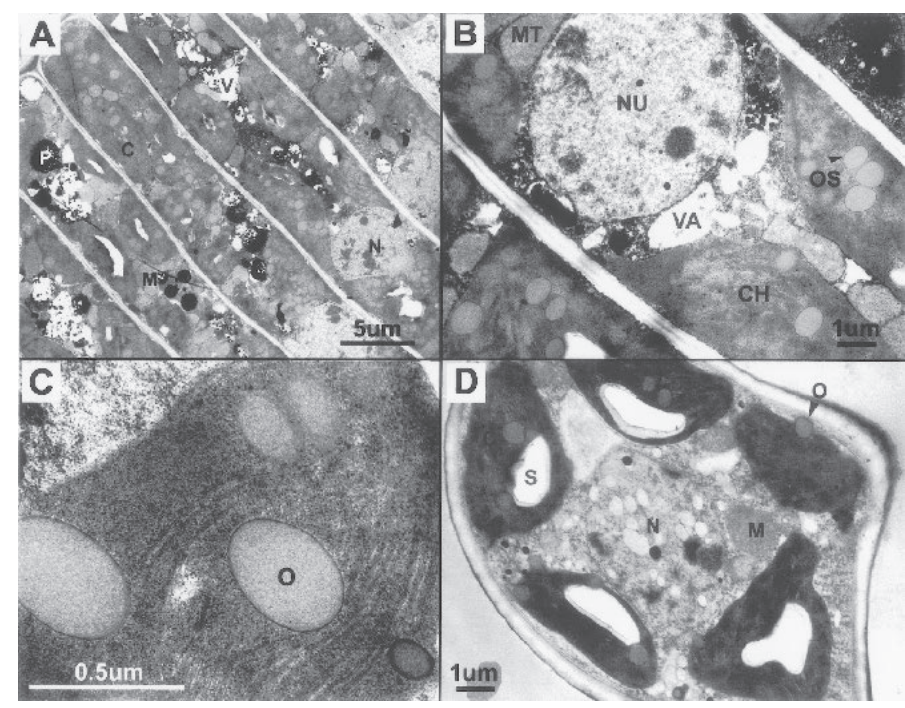

Fig. 3. Transmission electron micrographs of control leaves grown in the presence of zinc. (A) Elongated palisade parenchyma cells were closely packed with few intercellular spaces. Cells had high cytoplasmic content and limited vacuolar spaces. (B) Higher magnification showing nucleus and numerous chloroplasts. (C) Chloroplast with osmiophilic globules and granal stacks. (D) Spongy mesophyll cell showing nucleus and chloroplasts with occasional starch grain formation $. \mathrm{c}=$ chloroplast, $\mathrm{m}=$ mitochondrium, $\mathrm{nu}=$ nucleus, $\mathrm{o}=$ osmiophillic globule, $\mathrm{p}=$ phenolic compounds, $\mathrm{s}=$ starch, $\mathrm{va}=$ vacuole 


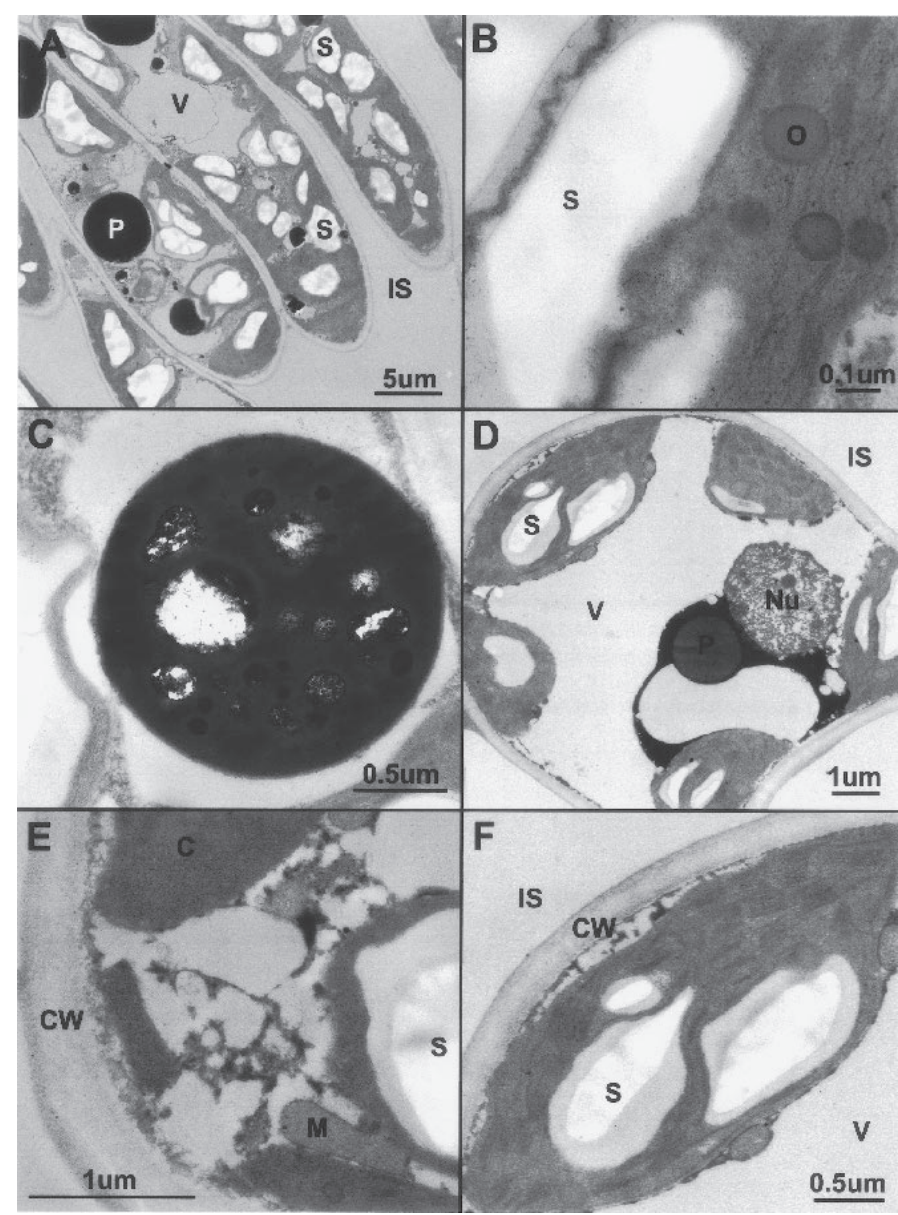

Fig. 4. Transmission electron micrographs of zinc deficient leaves with intermediate deficiency symptoms. (A) Palisade parenchyma cells were irregularly shaped and had extensive intercellular spaces. (B) Higher magnification of a chloroplast showing numerous starch deposits. (C) Vacuolar region showing accumulation of phenolic components in a palisade parenchyma cell. (D) Spongy mesophyll cell with large central vacuole and parietal cytoplasm; chloroplasts had numerous starch deposits. (E) Region of a spongy parenchyma cell showing vesicle formation and breakdown of cytoplasm. (F) Region adjacent to cell wall showing separation of the plasma membrane. $\mathrm{c}=$ chloroplast, $\mathrm{cw}=$ cell wall, is = intercellular space, $\mathrm{m}=$ mitochondrium, $\mathrm{nu}=$ nucleus, $\mathrm{o}=$ osmiophillic globule, $\mathrm{p}=$ phenolic compounds, $\mathrm{s}=$ starch, $\mathrm{v}=$ vacuole.

individual shoot basis. Because values obtained on an orchard basis are from composite samples of normal and deficient leaflets, foliar concentrations recommended to prevent deficiency symptoms are elevated to correct for dilution effects from normal leaflets and the large variability in zinc concentrations observed among trees. The zinc concentration obtained in the current study for normal leaf tissue $\left(11.15 \mu \mathrm{g} \cdot \mathrm{g}^{-1}\right)$ is similar to levels determined in other studies evaluating individual shoots, i.e., zinc sufficiency was reported to be about $14 \mu \mathrm{g} \cdot \mathrm{g}^{-1}$ (Hu and Sparks, 1990; Hu and Sparks, 1991) at which level no visible signs of deficiency or inhibition of reproductive development were observed.

Leaves that developed under complete nutrient conditions exhibited typical features of pecan leaves (Fig. 2A). The upper and lower epidermis were uniserate, and mesophyll cells were differentiated into distinct palisade and spongy regions. The palisade cells had few intercellular spaces. Both palisade and spongy mesophyll cells had abundant cytoplasm, numerous chloroplasts, and few vacuoles. The spongy region had extensive intercellular spaces. In contrast, zinc deficient leaves (Fig. 2B-D) exhibited divergent cell arrangements. Leaves showing mild visual symptoms (Fig. 2B) had palisade cells that were wider, shorter, and more vacuolate than leaves with sufficient zinc. Intercellular spaces in the palisade were more numerous. Epidermal and spongy mesophyll cell size increased in deficient leaves. Spongy cells were highly vacuolate. In leaves exhibiting intermediate zinc deficiency ratings (Fig. 2C), cellular deficiency characteristics became more exaggerated as zinc deficiency increased. Palisade cells were progressively shorter and wider. Additionally, darkly staining material resembling phenolic components were found in the vacuoles, especially in palisade cells. In leaves with severe deficiency symptoms (Fig. 2D), mesophyll cells developed numerous small vesicles. Loss of cellular integrity was observed in some areas.

Leaf thickness, palisade layer thickness, spongy layer thickness, epidermis cell height, and palisade cell width were quantified in leaves with different $\mathrm{Zn}$ deficiency symptom ratings (Table 1). As symptoms became more severe, leaf thickness and the height of the palisade and spongy layers decreased. Epidermal cell height increased with symptom rating. The number of palisade cells per length along the leaf surface decreased as a result of wider palisade cells interspersed with more extensive intercellular spaces. Anatomical differences were more marked as the symptoms in leaves progressed to the intermediate-deficiency condition. Leaves exhibiting intermediate versus severe deficiency symptoms showed little difference in anatomical characteristics.

In leaves with mild deficiency symptoms, cell structures varied depending on the location of cells evaluated. Leaf chlorosis was interspersed with predominantly green sectors exhibiting no deficiency symptoms. Thus, transmission electron microscopy of leaves with intermediate symptoms is presented to illustrate the ultrastructural characteristics of zinc deficiency (Fig. 3).

Leaves from plants grown with zinc had elongated palisade cells which were closely packed with few intercellular spaces (Fig. 3A). Cells had a high cytoplasmic content and limited vacuolar space. Palisade cells exhibited well-delimited nuclei, and mitochondria were prevalent (Fig. 3B). Chloroplasts had osmiophilic lipid globules, and internal membranes were organized into granal stacks (Fig. 3C). Starch was observed occasionally in the chloroplasts. Cells in the spongy mesophyll also exhibited high cytoplasmic content and dominant chloroplasts with occasional starch grain formation (Fig. 3D).

In zinc-deficient leaves, palisade cells were more irregularly shaped and had more extensive intercellular spaces (Fig. 4A). Chloroplasts were still prevalent but characterized by extensive starch deposits (Fig. 4A and B). Internal membranes maintained their integrity and osmiophilic globules were observed. Cells had wide vacuolar spaces that frequently had extensive accumulations of darkly staining materials resembling phenolic compounds (Fig. 4A and C). The number of mitochondria was fewer than in zinc-sufficient leaves. Spongy cells in zinc-deficient leaves exhibited large vacuoles with the cytoplasm restricted to parietal areas (Fig. 4D). Phenolic accumulation occurred within the vacuoles. In some cases, loss of cell integrity was associated with precipitates in cytoplasm regions (Fig. 4E). The plasma membrane separated from the cell wall in some areas (Fig. 4F). Severely deficient leaves had necrotic areas. Characterizing cell death changes would provide limited insight into changes induced by the lack of zinc. Furthermore, anatomical differences in cell size and number were similar in comparisons between leaves with intermediate versus severe deficiency (Table 1). Therefore, severely deficient samples are not described. 
Before the current study, cytological and ultrastructural characteristics associated with zinc deficiency had not been well defined. Samsidar and Gomez (1980) conducted structural evaluations of a number of macro- and micronutrient deficiencies in Hevea. Similar to our results, they reported that zinc deficient leaves exhibited decreased palisade cell length, increased intercellular space, and extensive accumulation of starch grains in chloroplasts. However, their microscopic evaluations were limited, and induction of deficiencies was not described.

The accumulation of starch observed in zinc deficient pecan leaves concurs with biochemical studies reporting an accumulation of sucrose and starch in other species including maize (Zea mays L.) and bean (Phaseolus vulgaris L.) (Cakmak et al., 1989; Sharma, 1983). Accumulation of carbohydrates was attributed to impaired phloem export. In contrast, zinc deficiency decreased sucrose concentration and sucrose synthase activity in sugarbeet (Brassica napus L.) (Bravo et al., 1992) and maize (Shrotri et al., 1980). Brown and Sidhu (1992) attributed decreased starch formation under zinc deficiency to a reduction in starch synthase activity.

This study delineates morphological, anatomical, and ultrastructural characteristics of zinc deficiency in leaves. Mild zinc deficiency symptoms were characterized by interveinal mottling. Leaves with intermediate symptoms exhibited interveinal chlorosis and necrotic lesions, while severe symptoms included extensive necrosis and marginal curving. Structural differences associated with zinc deficiency included decreases in leaf thickness and changes in mesophyll cell organization. Cells in zinc deficient leaves had limited cytoplasmic content and accumulated phenolic compounds in vacuoles. Extensive starch accumulation was observed in chloroplasts. This work represents the first detailed microscopic evaluations of zinc deficiency in leaves, and provides insight on how zinc deficiency affects leaf structure and function.

\section{Literature Cited}

Arce, J.P., J.B. Storey, and C.G. Lyons. 1992. Effectiveness of three different zinc fertilizers and two methods of application for the control of "little leaf" in peach trees in south Texas. Commun. Soil Sci. Plant Anal. 23:1945-1962.

Bell, P.F., J.A. Vaughn, and W.J. Bourgeois. 1997. Leaf analysis finds high levels of chloride and low levels of zinc and manganese in Louisiana citrus. J. Plant Nutr. 20:733-743.

Bravo, S., G.S. Lee, and W.R. Schmehl. 1992. Effect of planting date, nitrogen fertilizer and harvest date on seasonal concentrations and total content of five micronutrients in sugarbeet. J. Sugar Beet Res. 29:4557.

Brown, D.H. and M. Sidhu. 1992. Heavy metal uptake, cellular location, and inhibition of moss growth. Cryptogamic Bot. 1:82-85.

Cakmak, I., H. Marschner, and F. Bangerth. 1989. Effect of zinc nutritional status on growth, protein metabolism and levels of indole3 -acetic acid and other phytohormones in bean. J. Expt. Bot. 40:405412.

Cakmak, I., N. Sary, H. Maschner, A. Kalayc, A. Yilmaz, S. Eker, and K. Y. Gulut. 1996. Dry matter production and distribution of zinc in bread and durum wheat genotypes differing in zinc efficiency. Plant and Soil 180:173-181.
Edwards, E.G. and A.K. Mohamed. 1973. Reduction in carbonic anhydrase activity in zinc deficient leaves of Phaseolus vulgaris L. Crop Sci. 13:351-354.

Ganai, R., M.K. Sinha, and B. Prasad. 1982. Parameters of availability of zinc in orchard soils in relation to zinc nutrition of apple. Plant and Soil 66:91-99.

Graham, R.D., J.S. Ascher, and S.C. Hynes. 1992. Selecting zincefficient cereal genotypes for soils of low zinc status. Plant and Soil 146:241-250.

Hoagland, D.C. and D.I. Arnon. 1950. The water culture method for growing plants without soil. Calif. Agr. Expt. Sta. Circ. 347.

Hu, H. and D. Sparks. 1990. Zinc deficiency inhibits reproductive development in 'Stuart' pecan. HortScience 25:1392-1396.

$\mathrm{Hu}, \mathrm{H}$. and D. Sparks. 1991. Zinc deficiency inhibits chlorophyll synthesis and gas exchange in 'Stuart' pecan. HortScience 26:267268.

Jolley, V.D. and J.C. Brown. 1991. Factors in iron-stress response mechanism enhanced by Zn-deficiency stress in Sanilac, but not Saginaw navy bean. J. Plant Nutr. 14:257-265.

Kim, T.R., H.A. Mills, and H.Y. Wetzstein. 2002. Studies on the effect of zinc supply on the growth and nutrient uptake of pecan. J. Plant Nutr. 25(9):1987-2000.

Marschner, H. 1997. Mineral nutrition of higher plants. Academic Press, San Diego.

Mengel, K. and E.A. Kirkby. 1982. Principles of plant nutrition. Intl. Potash Inst., Bern.

Parker, D.R. 1992. Zinc-phosphorus interactions in two cultivars of tomato (Lycopersicon esculentum L.) grown in chelator-buffered nutrient solutions. Plant and Soil 143:163-177.

Randall, P.J. and D. Bouma. 1973. Zinc deficiency, carbonic anhydrase, and photosynthesis in leaves of spinach. Plant Physiol. 52:229-232.

Rengel, Z. 1995. Carbonic anhydrase activity in leaves of wheat genotypes differing in zinc efficiency. J. Plant Physiol. 147:251-256.

Reynold, E.S. 1963. The use of lead citrate in high pH as an electronopaque stain in electron microscopy. J. Cell. Biol. 17:108-212.

Samsidar, B.H. and J.B. Gomez. 1980. Ultrastructure of mineral deficient leaves of Hevea. II. Effects of micronutrient deficiencies. J. Rubber Res. Inst. Malaysia. 28:17-25

Sharma, R.N. 1983. A short note on response of maize to rates, time and method of zinc application. Indian J. Agron. 28:469-470.

Shrotri, C.K., M.N. Tewari, and V.S. Rathore. 1980. Effect of zinc nutrition on sucrose biosynthesis in maize. Phytochemistry 19:139_ 140.

Smith, M.W. 1991. Pecan nutrition, p. 152-158. In: B.W. Wood and J.A. Payne (eds.). Pecan husbandry: Challenges and opportunities. USDAARS.

Snir, I. 1983. Carbonic anhydrase activity as an indicator of zinc deficiency in pecan leaves. Plant and Soil 74:287-289.

Sparks, D. 1976. Nitrogen scorch and the pecan. Pecan S. 3:500-501.

Sparks, D. 1989. Pecan nutrition-A review. Proc. SE Pecan Growers Assn. 82:101-122.

Sparks, D. 1993. Threshold leaf levels of zinc that influence nut yield and vegetative growth in pecan. HortScience 28:1100-1102.

Sparks, D. and J.A. Payne. 1982. Zinc concentration in pecan leaflets associated with zinc deficiency symptoms. HortScience 17:670-671.

Spencer, D. and J.V. Possingham. 1960. The effect of nutrient deficiencies on the Hill reaction of isolated chloroplasts from tomato. Austral. J. Biol. Sci. 13:441-455.

Spurr, A.R. 1969. A low-viscosity epoxy resin embedding medium for electron microscopy. J. Ultrastruct. Res. 26:31-43. 